\title{
A EDUCAC̣ÃO ESCOLAR, A EXCLUSÃO E SEUS DESTINATÁRIOS
}

\author{
Carlos Roberto Jamil Cury*
}

PUCMINAS

RESUMO: A educação escolar, similarmente a outras dimensões da vida sociocultural, coexiste, em países marcados pela desigualdade, com o fato de ser inclusiva e seletiva nos modos e meios dessa inclusão educacional e estar, ao mesmo tempo, sob o signo universal do direito. Nesse raciocínio, faz sentido perguntar quem são os "herdeiros" e/ou os reais atingidos pela privação dessa destinação universal da educação escolar como direito específico. E esse raciocínio deve desembocar em outra pergunta que, logicamente, se sucede ao para quem. Trata-se, igualmente, de interrogar o para quê dessa inclusão excludente.

PALAVRAS-CHAVE: Escolar; Inclusão; Exclusão; Igualdade de oportunidades; Direito e efetivação

\section{TITLE}

ABSTRACT: In countries marked by inequality, school education, similarly to other social-cultural dimensions, coexist with inclusiveness and the selectiveness of ways and means of educational inclusion simultaneously with being considered a universal right. From this viewpoint, it makes sense to inquire who its "inheritors" are and/or who is actually affected by the privation of the universal right of education as a specific right. This reasoning logically leads to another question: who the clientele is. Thus, the aim is also to investigate the objective of exclusive inclusion.

KEYWORDS: School Education; Inclusion and Exclusion; School Education and Equal Opportunities; School Education, Right and Effectuation

* Professor Adjunto da Pontifícia Universidade Católica de Minas Gerais - PUCMINAS. E-mail: crjcury.bh@terra.com.br 


\section{INTRODUCุÃO}

A educação escolar, mercê de sua natureza conatural ao desenvolvimento das faculdades intelectuais do ser humano, graças ao potencial de sua vertente socializadora, veio se constituindo como um dos direitos mais importantes da cidadania.

Por sua natureza conatural e de suas funções maiores (ensino/aprendizagem e cidadania), poucos houve que não vissem nela um horizonte a ser universalizado no âmbito das sociedades, especialmente a partir da Modernidade. Basta chamar à cena Jan Amos Comenius $(1592$ - 1670) e seu ensinamento maior: o "ensinar tudo a todos", certamente uma formulação próxima do direito ao saber como um direito igualitário dentro da escola formal. ${ }^{1}$

Os novos tempos da Modernidade não seriam tais sem $\mathrm{O}$ concurso da escola como lugar do direito ao saber e da cidadania. A esse direito - conceituação duramente conquistada e formalizada pelas lutas sociais e parlamentares dos que compreenderam sua natureza e funções se impôs sua institucionalização e sua abertura como dever do Estado.

$\mathrm{Na}$ efetivação desse horizonte, não faltou quem visse na educação escolar somente uma função instrumentalizadora, própria do "indivíduo possessivo", sujeito apenas das relações contratuais de mercado. Não seria abusado chamar ao procênio a famosa frase de Adam Smith (1723 - 1790), retomada por Marx, no capítulo XII, livro I, de O Capital, que pregava "os pontos mais essenciais da educação, ainda que em doses homeopáticas a fim de evitar a degeneração completa da massa do povo, originada pela divisão do trabalho".

Mas pela natureza multiplicadora da relação pedagógica, ínsita no processo de constituição de conhecimentos pelo ensino/aprendizagem, a educação escolar rebela-se contra seu aprisionamento em uma dimensão exclusivamente instrumental. Daí a preocupação em torná-la constitutiva dos e nos vários códigos legais dos direitos subjetivos do indivíduo ut singulus e dos direitos sociais do cidadão ut socius.

Como assevera Bobbio (1992):

Não existe atualmente nenhuma carta de direitos que não reconheça o direito à instrução - crescente, de resto, de sociedade para sociedade - primeiro, elementar, depois secundária, e pouco a pouco até mesmo universitária. Não me consta que, nas mais conhecidas descrições do estado de natureza, esse direito fosse mencionado. A verdade é que esse direito não fora posto no estado de natureza porque não emergira na sociedade da época em que nasceram as doutrinas jusnaturalistas, quando as exigências fundamentais que partiam daquelas sociedades para chegarem aos poderosos da Terra eram principalmente exigências de liberdade em face das Igrejas e dos Estados, e não 
ainda de outros bens, como o da instrução, que somente uma sociedade mais evoluída econômica e socialmente poderia expressar.(p. 75)

Nossa Constituição da República de 1988 contém a assunção desse direito multidimensional quando, resguardando a personalidade, o trabalho e a participação cidadã, em seu art. 205 proclama:

A educação, direito de todos e dever do Estado e da família, será promovida e incentivada com a colaboração da sociedade, visando ao pleno desenvolvimento da pessoa, seu preparo para o exercício da cidadania e sua qualificação para o trabalho.

Contudo, a natureza universalista da assunção dos conhecimentos organizados e sistemáticos em níveis cada vez mais elevados encontra obstáculos difíceis de serem transpostos no interior de contextos sociais marcados pela desigualdade na apropriação dos bens socialmente produzidos.

Eis por que, mais recentemente, essas barreiras vêm sendo administradas pela categoria exclusão. A tal categoria, por vezes e abusivamente, atribui-se a capacidade de explicar os males de nossa sociedade.

A exclusão, contudo, não é um estado permanente, ela é, no dizer de Martins (1997)

... um momento da percepção que cada um e todos podem ter daquilo que concretamente se traduz em privação: privação do emprego, privação dos meios para participar do mercado de consumo, privação de bem-estar, privação de direitos, privação de liberdade, privação de esperança. (p. 18)

Por isso, não se pode torná-la um conceito de tal modo abrangente e genérico que venha a ser empregado para significar e conceituar todo e qualquer problema social, de qualquer momento histórico ou de qualquer contexto social. Desse modo, é preciso se interrogar se não seria mais acertado um conceito como inclusão excludente, sobretudo caso se considere a lógica do capitalismo. Martins (1997) parece afirmar que a exclusão é um nome para dizer do

... conjunto das dificuldades, dos modos e dos problemas de uma inclusão precária e instável, marginal. A inclusão daqueles que estão sendo alcançados pela nova desigualdade social produzida pelas grandes transformações econômicas e para os quais não há senão, na sociedade, lugares residuais. (p. 26)

Ou em outra passagem do mesmo autor: "A sociedade capitalista desenraiza, exclui, para incluir, para incluir de outro modo, segundo suas próprias regras, segundo sua própria lógica”. (p. 32) 
Eis que a educação escolar, similar a outras dimensões da vida sociocultural, então coexiste nessa contradição de ser inclusiva e seletiva nos modos e meios dessa inclusão e estar, ao mesmo tempo, sob o signo universal do direito. Ela não teve e ainda não tem sua distribuição efetivamente posta à disposição do conjunto dos cidadãos sob a égide da igualdade de oportunidades e de condições.

Nessa via de raciocínio, faz sentido perguntar sobre quem são os "herdeiros" e/ou os reais atingidos pela deserdação desta destinação universal, ou melhor, pela privação dessa destinação universal da educação escolar como um direito específico. E esse raciocínio deve desembocar em outra pergunta que, logicamente, se sucede ao para quem. Trata-se de interrogar o para quê dessa inclusão excludente.

\section{HERDEIROS E DESERDADOS NO BRASIL}

Se a inserção do direito à educação tornou-se, hoje, um princípio e uma norma do ordenamento jurídico brasileiro e se a atual realidade indica uma inclusão excludente e seletiva, então é preciso verificar também, na ordem legal, como o ontem o inscreveu, até por uma razão de ordem processual e de memória histórica.

Essa leitura pode tanto propiciar uma aproximação do processo histórico de cujo peso ainda hoje vemos as conseqüências, quanto pode nos permitir uma abertura para novas possibilidades.

Nossa Constituição Imperial de 1824, no capítulo das "Garantias dos Direitos Civis e Políticos dos Cidadãos Brasileiros" reconhece, no art. 179, XXXII, como direito dos mesmos "a instrução primária gratuita". Ora, o art. $6^{\circ}$ da mesma Constituição, ao definir o para quem dessa cidadania, tem como "cidadãos brasileiros os que no Brasil tiverem nascido, quer sejam ingênuos ou libertos”. Ora, os ingênuos são os que nasceram livres e filhos de pais livres. São os livres e naturais do país, são cidadãos ex generatione e ex jus soli. Já os libertos são aqueles alforriados que, libertandose da escravidão, recuperaram a sua condição de homens livres. Assim, por oposição, a Constituição Imperial não reconhece os escravos como cidadãos. Desse modo, o estatuto da escravatura, tacitamente acolhido, tem, por abjeto que seja, o outro como objeto, propriedade, mercadoria.

De acordo com Carvalho (2002):

...o fator mais negativo para a cidadania foi a escravidão. Calcula-se que até 1822 tenham sido introduzidos na Colônia cerca de 3 milhões de escravos. $\mathrm{Na}$ época da Independência, numa população de cerca de 5 milhões, incluindo uns 800 mil índios, havia mais de 1 milhão de escravos. (p. 19) 
Outro momento tácito de reconhecimento da escravidão está no mesmo art. 179, XIX que abole "os açoites, a tortura, a marca de ferro quente e todas as mais penas cruéis”.

Além dessa concepção hierárquica, socialmente abominável, de etnias e de nativos no trabalho escravo não se pode esquecer da concepção relativa aos índios. Para as elites, seu "estágio" no processo civilizatório é tido como o de "hordas selvagens". O Decreto Imperial n. 1.318, de 1854, regulamentando a lei n. 601, conhecida como Lei de Terras, tem os índios como aptos a serem segregados em aldeamentos para efeito de civilização e de catequese, de acordo com o art.11 do Ato Adicional de $1834 .^{2}$

À época da Independência, então, apenas por exclusão socioetnica, 40\% dos habitantes não só não teriam acesso à educação como também não eram tidos como cidadãos.

Se a isso ajuntarmos as mulheres, que, por uma concepção específica da época, as confinava aos limites da "cidadania passiva", então o universo dos não-cidadãos ou cidadãos "imperfeitos" sobe consideravelmente. À época, o direito de voto, privativo do sexo masculino, se regia pelo voto censitário, portanto baseado nos recursos pecuniários ou territoriais do seu possuidor.

Nossa primeira lei geral de educação de 1827, ao regulamentar o artigo da Constituição relativo à gratuidade da instrução primária, trará outra limitação, agora de ordem espacio-populacional, já no seu art. $1^{\circ}$, ipsis litteris: "Em todas as cidades, vilas e lugares mais populosos, haverão as escolas de primeiras letras que forem necessárias".

Tal limitação diz muito do interior do país, do isolamento da população residente em latifúndios monoculturais, na pecuária e mesmo em regiões de mineração. Diz muito quando dela se pode extrair uma conseqüência subjacente do tipo: que necessidade há em fornecer educação para esse pessoal? A que ela vai servir? Não será ela inútil para tais populações? Nesse sentido, a instrução destinar-se-ia, com as barreiras já assinaladas, aos moradores urbanos.

O ordenamento legal acrescenta outro limite à ampliação de sujeitos capazes das "primeiras letras" consoante a "instrução primária" gratuita posta na Constituição. Trata-se da descentralização administrativa, quando o Ato Adicional de 1834 transfere para as Províncias, destituídas de recursos advindos de impostos mais rentáveis, a competência legislativa "sobre a instrução pública" e, como já assinalado, "sobre a catequese e civilização dos indígenas". ${ }^{3}$ 
Decorrente dessas limitações em seu conjunto, não é de se admirar que uma lei provincial do Rio de Janeiro, a de n. 1 de 02/01/1837, escreva em seu art. $3^{\circ}$ :

São proibidos de freqüentar as escolas públicas:

$1^{\circ}$ : todas as pessoas que padecerem de moléstias contagiosas;

$2^{\circ}$ : os escravos e os pretos africanos, ainda que sejam livres ou libertos... ${ }^{4}$

Em 1888, a escravatura foi oficialmente abolida e, a seguir, instaura-se, em 1889, a República Federativa, representativa e presidencialista com a Constituição de $1891^{5}$. Com o fim do voto censitário em favor do voto universal, masculino e letrado, a instrução tornou-se condição de direitos políticos. O recorte liberal dessa Constituição deixou ao sujeito individual a procura pela educação escolar, silenciando-se quanto à gratuidade anteriormente posta. Ao âmbito federativo ficou a possibilidade de se afirmar, nas respectivas Constituições Estaduais, tanto a gratuidade quanto, eventualmente, sua associação com a obrigatoriedade.

Em vão foram as várias tentativas legais e pressões sociais, no período da Velha República, pela afirmação nacional e constitucional da gratuidade e de maior presença da União no ensino obrigatório. Nem mesmo a Revisão Constitucional de 1925/26, em cujo processo havia emenda nesse sentido, logrou êxito. ${ }^{6}$

Não admira, pois, que, pondo esperanças no futuro da Revolução de Trinta, o Manifesto dos Pioneiros da Educação Nova, de 19327, retrata assim o passado imperial e o republicano até então:

De fato, o divórcio entre as entidades que mantêm o ensino primário e profissional e as que mantêm o ensino secundário e superior vai concorrendo insensivelmente, como já observou um dos signatários deste Manifesto, 'para que se estabeleçam, no Brasil, dois sistemas escolares paralelos, fechados em compartimentos estanques e incomunicáveis, diferentes nos seus objetivos culturais e sociais, e, por isto mesmo, instrumentos de estratificação social'. (p. 40)

Esse trecho do Manifesto aponta para uma passagem de texto de Anísio Teixeira, signatário do Manifesto, o qual poderia se intitular Escola Capitalista no Brasil. Essa escola teria como característica a de possuir "dois sistemas" ou duas redes no sentido atribuído pelo mesmo Manifesto quando nele se opõe a educação a ser (re)construída àquela então existente. Continua o mesmo texto dizendo da escola projetada:

...desprendendo-se dos interesses de classes, a que ela tem servido, deixa de constituir um privilégio determinado pela condição econômica e social do indivíduo, para assumir um "caráter biológico", com que ela se organiza para a coletividade em geral, reconhecendo a todo o indivíduo o direito a ser 
educado até onde o permitam as suas aptidões naturais, independente de razões de ordem econômica e social. (p. 33)

Nesse jogo do conflito social, expresso na dialética privilégio $\mathrm{x}$ direito, expressões desse último pólo da relação comparecerão na Constituição de 1934: a educação como direito, a obrigação dos poderes públicos em prestá-la, no ensino primário, gratuita e obrigatoriamente nas escolas oficiais, a vinculação de percentuais dos impostos federativos para a educação e o estabelecimento de um plano nacional de educação. ${ }^{8}$

Contudo, no ensino ulterior ao primário, ainda que tendencialmente gratuito, haverá "limitação da matrícula à capacidade didática do estabelecimento e seleção...”, segundo a letra e do art. 150. Ou seja, para os que obtivessem seu certificado de conclusão do primário e quisessem prosseguir seus estudos, deveriam eles passar por exames de seleção, os conhecidos "exames de admissão". As vagas dependeriam da capacidade didática do estabelecimento e de sua gratuidade dependeria de legislação estadual.

Mas o retorno ao privilégio, ao elitismo e a destinação de classe socialmente prévia para a educação do "secundário/superior" ficaria meridianamente clara com o fim do frágil regime democrático de 1934 e com o estabelecimento do regime de facto, em 1937. ' A Constituição desse regime, denominado "Estado Novo", expressa nos seus artigos 125, 127 e 129, respectivamente, uma explícita visão organicista, hierárquica e elitista da educação e da sociedade:

A educação integral da prole é o primeiro dever e o direito natural dos pais. O Estado não será estranho a esse dever, colaborando, de maneira principal ou subsidiária, para facilitar sua execução ou suprir as deficiências e lacunas da educação particular.

A infância e a juventude devem ser objeto de cuidados e garantias especiais por parte do Estado, que tomará todas as medidas destinadas a assegurar-lhes condições físicas e morais de vida sã e de harmonioso desenvolvimento das suas faculdades.

À infância e à juventude a que faltarem os recursos necessários à educação em instituições particulares, é dever da Nação, dos Estados e dos Municípios assegurar, pela fundação de instituições públicas de ensino em todos os seus graus, a possibilidade de receber uma educação adequada às suas faculdades, aptidões e tendências vocacionais.

$\mathrm{O}$ ensino pré-vocacional e profissional destinado às classes menos favorecidas é em matéria de educação o primeiro dever do Estado. Cumpre-lhe dar execução a esse dever, fundando institutos de ensino profissional e subsidiando os de iniciativa dos Estados, dos Municípios e dos indivíduos ou associações particulares e profissionais. 
A teoria dos dois sistemas, segundo Anísio Teixeira, ou, como prefere a sociologia educacional francesa, a teoria das duas redes, não poderia ser mais clara. Mas teve um outro reforço legal. É o Decreto n. 4.244/42, em seu art. 22, relativo aos "herdeiros" Reforma do Ensino Secundário: “...é finalidade da educação secundária formar as individualidades condutoras pelo que força é desenvolver nos alunos a capacidade de iniciativa e de decisão e todos os atributos fortes da vontade".

Por oposição, os destinatários do ensino profissional são os que a Constituição de 1937 denominava de "classes menos favorecidas".

Há aqui duplo dualismo: a escola pública é voltada para os que não conseguem entrar em escola particular, a qual, por sua vez - extensão da família -, deve ser subsidiada pelo Estado, formando as "elites condutoras". ${ }^{10} \mathrm{E}$ a escola pública, voltada para as "classes menos favorecidas", tem na educação primário-profissional o seu lugar natural "de receber uma educação adequada às suas faculdades, aptidões e tendências vocacionais", segundo o teor do mesmo do art. 129 da Constituição de então.

A superação desse duplo dualismo franco, explícito e seletivo seria objeto de passos lentos em vista da equiparação do ensino profissional com o ensino secundário e a possibilidade de prossecução em estudos superiores. ${ }^{11}$

A Constituição de 1946 retoma princípios da de 1934, tais como o da vinculação de impostos para o financiamento, a educação como direito, a gratuidade e obrigatoriedade do ensino primário.

Sob essa Constituição, após debates intensos e apaixonados entre publicistas e privatistas, vem à tona a Lei de Diretrizes e Bases da Educação Nacional, prevista na Constituição, sob a lei n. 4.024/61. ${ }^{12}$ Essa lei deixa abertas brechas para que o ensino primário obrigatório não fosse integralmente cumprido. Seu art. 30, ao explicitar as isenções da obrigatoriedade, deixa claro quem "não precisa" ser destinatário da educação escolar: os que comprovarem "estado de pobreza", os que não puderem ir à escola por haver "insuficiência de escolas" ou por estas já terem suas "matrículas encerradas". Além desses casos, incluem-se os indivíduos que estejam com alguma "doença ou anomalia grave".

Raramente a face da desigualdade social, fruto de relações econômicas, sociais, políticas e culturais, foi tão clara: o indivíduo em "estado de pobreza" está privado das virtudes de um direito proclamado como essencial para a vida social. Mas, certamente, não está excluído de continuar sendo mantido "clientelisticamente" nos espaços de um trabalho rural. Também o cidadão cujo município ou região do Estado careça 
de recursos para abertura de escolas ou de vagas para todos também pode ser desobrigado da freqüência à escola. Seus cidadãos, contudo, não estão proibidos de serem sujeitos ao trabalho precário.

A face manifesta dessa inclusão excludente é a privação de determinados direitos e bens sociais para ser, ao mesmo tempo, precariamente incluído em outras dimensões da produção da existência social. ${ }^{13}$ Vale lembrar que, até hoje, o Brasil conta com muitas crianças sob a égide da perversidade do trabalho infantil. Desse modo, as franquias postas na lei n. 4.024/61 fragilizam até mesmo o Código Penal, que, em seu art. 246, estabelece penas para "o crime de abandono intelectual" por parte dos pais ou responsáveis que não enviam seus filhos para a escola.

A falta de acesso à educação escolar patenteia a causa mais profunda: a desigualdade social associada à fragilidade no pacto federativo. Essa situação tão clara não poderia deixar de impactar os sistemas de ensino no que se refere à qualidade do ensino/aprendizagem ofertados.

O golpe militar de 1964, ao lado da maior precariedade no regime federativo, trará novos impactos para a educação escolar. A frágil Constituição de 1967 subtrai da educação a vinculação no momento em que essa mesma Lei ampliava o ensino primário para 8 anos e o tornava obrigatório apenas para a faixa etária de 7 a 14 anos. E esse foi o momento em que a migração rural para os centros urbanos começava a exigir expansão da rede física e a formação docente que considerasse o novo perfil de aluno entrante nos sistemas públicos, perfil advindo de vários segmentos das classes populares. Dessa época, ainda, tem-se a maior facilidade, sob precários regimes contratuais, de entrada de docentes nos sistemas de ensino em geral, de formados em instituições destituídas da integração ensino/pesquisa e de qualidade limitada.

Esse processo de produção da desigualdade, de cujo peso a realidade atual ainda é detentora, vai nos mostrando a face dos sujeitos da privação: negros, pardos, migrantes do campo e de regiões mais pobres do país, trabalhadores manuais, moradores de bairros periféricos e pessoas fora da faixa etária legal.

Mas é preciso dizer que data dessa época a crescente demanda por escolarização primária, dado o surto de crescimento econômico pelo qual o país passava, aliado à urbanização desordenada e à forte industrialização nos grandes centros urbanos. Sem a devida redistribuição da riqueza produzida, o fosso entre ricos e pobres se aprofunda, realidade essa evidenciada por inúmeras estatísticas do período. 
A busca pela redemocratização do país, à vista da brutal desigualdade na redistribuição da renda, à vista de um desenho pouco animador do pacto federativo, conduziu a uma impressionante mobilização popular. Renascem os sonhos, sobem as expectativas, desenha-se a vontade de uma realidade mais promissora, mais democrática e mais justa.

A Constituição de 1988 exibe, na proclamação de direitos da cidadania, na assinalação de novas obrigações do Estado, a vontade de fazer, no país, no presente, um acerto de contas com a modernidade, expurgando do passado um enorme passivo com a justiça e com a democracia.

Aí a educação torna-se o primeiro dos direitos sociais (art. $6^{\circ}$.), o ensino fundamental, gratuito e obrigatório, ganha a condição de direito público subjetivo, os sistemas de ensino passam a coexistir em regime de colaboração recíproca, a gestão democrática torna-se princípio dos sistemas públicos de ensino e a gratuidade, em nível nacional e para todos os níveis e etapas da escolarização pública, se torna princípio de toda a educação nacional. $\mathrm{O}$ texto constitucional reconhece o direito à diferença de etnia, de idade, de sexo e situações peculiares de deficiência. ${ }^{14}$

Pode-se constatar, assim, como o Brasil avançou em sua legislação em matéria de reconhecimento de direitos ${ }^{15}$ - o que não pode ser minimizado - mas, ao mesmo tempo, como estamos longe de estabelecermos um patamar que seja condizente com esses valores, princípios e normas, os quais, em última instância, expressam o desejo de milhares de brasileiros.

\section{EDUCAC̣ÃO E SOCIEDADE}

O contraste entre a real situação do país e a necessidade de eliminar várias dessas marcas anacrônicas face à modernidade, das injustiças existentes face aos direitos sociais proclamados e do autoritarismo face à democracia ganha relevo e apoio no texto constitucional. Prova disso é o art. $3^{\circ}$ da Constituição, que põe como objetivos fundamentais do Estado Democrático de Direito a busca de uma sociedade livre, justa e solidária, a redução das desigualdades sociais, das disparidades regionais e das discriminações que ofendem a dignidade da pessoa humana.

Em que pesem os avanços conquistados na educação escolar, desde então, como a proximidade da universalização do ensino fundamental, a disciplinarização do financiamento, a ampliação do ensino médio e a discreta abertura na educação infantil, há muito o que fazer. $\mathrm{O}$ diagnóstico do Plano Nacional da Educação, lei n. 10.171/01, é claro: 
estamos falhando nas metas da quantidade, especialmente na educação infantil, no ensino médio, na educação de jovens e de adultos e na educação especial. E, no atingimento da qualidade, as coisas beiram o fracasso. Mais ainda, os sujeitos vitimizados continuam a ser os mesmos: negros, índios, migrantes, moradores da periferia, pessoas com mais idade. Em uma palavra: os que são vítimas de uma renitente e injusta distribuição da renda. Daí que situações de desigualdade, de disparidade e de discriminação produzidas de fora da escola acabam por reforçar situações de precariedade no interior dela.

A inclusão excludente responde, pois, "pela opção preferencial pelas classes populares" isto é : pelos que possuem baixa renda no âmbito social, pelos que procedem de regiões mais díspares e menos desenvolvidas do país e pelos que padecem discriminações de toda sorte, que vão do puro preconceito às práticas atentatórias aos direitos humanos.

Vale lembrar que o Programa de Promoção de Reforma Educativa da América Latina e Caribe (PREAL), em 2001, exarou um documento no qual reavalia as reformas educacionais havidas nos anos $1990 \mathrm{e}$ contém algumas considerações bastante importantes no que tange à relação desigualdade social e educação. ${ }^{16}$

Os 10\% mais ricos das pessoas de 25 anos de idade possuem entre 5 e 8 anos a mais de escolaridade que os $30 \%$ mais pobres.

Em quase todos os países para os quais se dispõe de dados, o fato de viver em zonas rurais agrava as desigualdades educacionais.

A disparidade no desempenho dos alunos reflete as desigualdades no acesso a uma educação de qualidade.

Certos grupos étnicos e raciais são particularmente desfavorecidos.

Com relação à eqüidade em termos de gênero, a situação da América Latina é relativamente boa.

Hoje, até mesmo setores mais conservadores do espectro político reconhecem que os graves problemas sociais extra-escolares interfe-rem negativamente no acesso, na trajetória e no desempenho dos alunos procedentes de famílias de baixa renda não foi prioridade nem em políticas públicas, nem na ação de significativos segmentos das elites. $O$ "empurraempurra" entre os poderes gerais do Império e dos poderes provinciais, a iniqüidade da escravatura, a descentralização sem recursos desde o Ato Adicional e a perversa distribuição da renda geraram uma herança até hoje pesada e não superada e que articula fatores sociais, étnicos, espaciais, regionais e o acesso, a permanência e o desempenho qualitativo na escola.

Comenta a esse respeito, no citado documento da PREAL (2001), o prof. Juan Carlos Tedesco: 
Quisiera expresar, en el marco de un acuerdo general sobre el documento, dos preocupaciones que deberían ser tenidas en cuenta en los análisis y las propuestas que formulamos sobre estrategias de reforma educativa. La primera de ellas se refiere a las características del actual contexto económico, social y cultural en el cual se desarrollan las reformas educativas. En muchos países de la región está aumentando la pobreza, la desigualdad social, la concentración del ingreso y la pérdida de capital social por la desconfianza creciente en las instituciones.

Estos fenómenos - ampliamente documentados por las evidencias empíricas disponibles - están asociados estrechamente a los bajos resultados de la educación. Todos estamos de acuerdo en sostener que la educación es un factor importante de equidad social, pero en el contexto actual de América Latina también es importante reconocer que un nivel básico de equidad social es condición necesaria para que la acción educativa sea exitosa. (p. 26)

Desse modo, ao não ignorar a situação socioeconômica de desigualdade, recupera-se a correlação sociedade e educação e seu impacto sobre o ensino/aprendizagem. Com isso evita-se exigir da ou até inculpar a escola pelo que não é de sua responsabilidade. Considerar esse ângulo é um passo importante para se pensar políticas públicas de cunho redistributivista, maior financiamento para a educação, os planos de carreira do magistério a partir de bases salariais recompostas.

Por outro lado, o reconhecimento do condicionamento socioeconômico sobre a educação não significa negar ou mascarar a dinâmica interna, responsabilidade própria das escolas e suas conseqüências na trajetória e no desempenho dos estudantes e de seus agentes como empenho profissional, projeto pedagógico, atualização de saberes e responsividade social e profissional.

O conhecimento escolar, hoje bastante pesquisado, vem sendo visto como um fato de seleção (ou não) e de poder face à dinâmica do cotidiano escolar. ${ }^{17}$

\section{CONSIDERANDO...}

A nossa legislação, certamente perfectível em muitos aspectos, tem um tom bastante avançado e, sem dúvida, contém elementos normativos em seus princípios que fazem jus a uma concepção democrática.

Como assevera Bobbio (1992, p. 79-80)

a existência de um direito, seja em sentido forte ou fraco, implica sempre a existência de um sistema normativo, onde por "existência" deve entender-se tanto o mero fator exterior de um direito histórico ou vigente quanto o reconhecimento de um conjunto de normas como guia da própria ação. A figura do direito tem como correlato a figura da obrigação. 
Políticas inclusivas supõem uma adequação efetiva ao conceito avançado de cidadania coberto pelo ordenamento jurídico do país.

Por outro lado, o mesmo Bobbio (1992, p. 10) adverte:

A linguagem dos direitos tem indubitavelmente uma grande função prática, que é emprestar uma força particular às reivindicações dos movimentos que demandam para si e para os outros a satisfação de novos carecimentos materiais e morais, mas ela se torna enganadora se obscurecer ou ocultar a diferença entre o direito reivindicado e o direito reconhecido e protegido. Não se poderia explicar a contradição entre a literatura que faz a apologia da era dos direitos e aquela que denuncia a massa dos "sem direitos". Mas os direitos de que fala a primeira são somente proclamados nas instituições internacionais e nos congressos, enquanto os direitos de que fala a segunda são aqueles que a esmagadora maioria da humanidade não possui de fato (ainda que sejam solene e repetidamente proclamados.

O avanço no ordenamento jurídico, evidentemente muito diferente e superior do que se conheceu no passado, o contínuo pleito dos educadores e cientistas por melhor educação e até mesmo o empenho dos governos até agora realizado, apesar dos avanços alcançados, não foram suficientes para fazer da inclusão um patamar de maior equidade na vida social. A realidade continua apresentando um quadro muito aquém dos benefícios que a educação desencadeia para o conjunto social e se encontra longe das promessas democráticas que ela encerra.

A retração do Estado, forçosa em alguns casos, funcional noutros, não pode se efetivar em omissão diante de situações de desigualdade, disparidade, discriminação e privilégios. E nem pode exonerar-se do seu papel de garantia do direito à educação como inalienável à pessoa e à sociedade. É dele, sobretudo, que a sociedade continua esperando condições para a ultrapassagem de situações de excludência, vindas do passado e aliadas a outras nascidas dos tempos presentes.

Estamos diante de um desafio instaurador de um processo que amplia a democracia e educa para a cidadania, rejuvenesce a sociedade e irriga a economia.

Estamos diante da necessidade de uma saída urgente para uma educação de qualidade. Uma saída que obedeça aos ditames da razão que a educação inaugura. O Estado que não assume essa via decreta sua perdição. A sociedade que não busca essa saída aceita a autoridade da submissão e refuga o caminho da autonomia.

Sabendo-se que a inclusão excludente é uma necessidade sob o capitalismo, sabendo-se que a resistência a essa forma precária de inclusão 
também se dá sob forma de inconformismo como negação dessa necessidade, não se pode ignorar os movimentos de busca e superação. Ela tanto pode ser uma forma de resistência a uma suposta condenação quanto a procura por outros horizontes, mais equânimes, mais emancipatórios.

Para sair de uma condição que nos constrange, em vários aspectos, a um confinamento educacional próprio do século XIX, é preciso considerar as mediações que possibilitem aos grupos sociais e ao Estado a pactuação de um novo esforço em prol da educação, sem o qual não ultrapassaremos os limites dos avanços até agora celebrados em boa parte em solenes proclamações. E uma dessas mediações é uma política de Estado que, atendendo o interesse maior de todos, presentifique o potencial da educação, superando as barreiras que impedem a construção de uma democracia mais ampla.

Se quisermos associar democracia e modernidade, ou o país como um todo toma a decisão inadiável e necessária de priorizar a educação básica como tarefa inadiável ou perderemos a velocidade da História em vista da construção de um espaço social que seja inclusivo de mais igualdade e mais liberdade.

\section{REFERÊNCIAS}

BOBBIO, Norberto. A era dos direitos. Rio de Janeiro: Campus, 1992.

BUFFA, Ester. Ideologias em conflito: escola pública e escola privada. São Paulo: Cortez e Moraes, 1979.

COMENIUS, Jan Amos. Didactica Magna. São Paulo: Martins Fontes, 2006.

CARVALHO, José Murilo de. Cidadania no Brasil: o longo caminho. Rio de Janeiro: Civilização Brasileira, 2002.

CUNHA, Célio. Educação e autoritarismo no Estado Novo. São Paulo: Cortez, 1981.

CUNHA, Luiz Antonio. O ensino profissional na irradiação do industrialismo. São Paulo: UNESP; Brasília: FLACSO, 2000.

CURY, Carlos Roberto Jamil. Cidadania republicana e educação: governo provisório do Mal. Deodoro e Congresso Constituinte de 1890-1891. Rio de Janeiro: DP\&A, 2001.

CURY, Carlos Roberto Jamil. A educação na revisão constitucional de 1925-1926. Bragança Paulista: EDUSF, 2003.

CURY, Carlos Roberto Jamil. Os fora de série na escola. Campinas: Autores Associados, 2005.

FÁVERO, Osmar (Org.). A educação nas constituintes brasileiras. 2 ed. Campinas: Autores Associados, 2001.

FORQUIN, Jean-Claude et al. Sociologia da educação: dez anos de pesquisa. Petrópolis: Vozes, 1995.

HORTA, José Silvério Bahia. O bino, o sermão e a ordem do dia: regime autoritário e educação no Brasil. Rio de Janeiro: UFRJ, 1994.

MACHADO, Regina Lucília Machado de Souza. Educação e divisão do trabalho. São Paulo: 
Cortez e Associados, 1989

MARTINS, José de Souza. Exclusão social e a nova desigualdade. São Paulo: Paulus, 1997. MARX, Karl. O Capital: crítica da economia política. São Paulo: Abril Cultural, 1983, vol. I, t. I.

MELLO, Guiomar Namo de. Fatores intra-escolares como mecanismos de seletividade no ensino de $1^{\circ}$ Grau. Educação e Sociedade, n. 2. São Paulo, 1979.

MOREIRA, Antonio Flávio. Sociologia do Currículo: origens, desenvolvimento e contribuições. Em Aberto, n. 46, 1990.

NOSELLA, Maria de Lourdes Deiró. As belas mentiras: a ideologia subjacente aos textos didáticos. São Paulo: Cortez e Moraes, 1979.

ROCHA, Marlos Bessa Mendes da. Tradição e Modernidade na Educação: o processo constituinte de 1933-34. In: FÁVERO, Osmar (Org). A educação nas constituintes brasileiras. 2. ed. Campinas: Autores Associados, 2001.

ROSENBERG, Fúlvia. Discriminações étnico-raciais na literatura infanto-juvenil brasileira. Tempo Brasileiro, n. 63, São Paulo, 1990.

SAVIANI, Dermeval. Educação brasileira: estrutura e sistema. São Paulo: Saraiva, 1973.

SBPC. Documenta. Educação n. 3 A (Re) Construção da Educação no Brasil. São Paulo: SBPC, 1995.

SMITH, Adam. A riqueza das nações: investigação sobre sua natureza e suas causas. São Paulo: Abril Cultural, 1983. v. II.

SOARES, José Francisco. O efeito da escola no desempenho cognitivo de seus alunos. In: SOUZA, Alberto de Mello e (Org.). Dimensões da avaliação educacional. Petropólis: Vozes, 2005. p. 174-204.

YOUNG, Michael. O currículo do futuro: da nova sociologia da educação a uma teoria crítica da aprendizagem. Campinas: Papirus, 2000.

\section{NOTAS}

${ }^{1}$ Cf. Comenius, 2006.

2 De acordo com Martins (1997, p. 30-31), "...tivemos duas escravidões: a indígena e a negra, cada uma regulada por um estatuto jurídico diferente. (...) É no século dezoito, porém, que se dá uma cessação mais ou menos eficaz da escravidão indígena. $O$ Diretório dos Índios do Maranhão e do Grão-Pará liberta os índios administrados, nome que tinha a sua escravidão. Eles passam, então à condição de teoricamente livres e, na prática, mais ou menos servos dependentes do grande proprietário. Milhões de indígenas foram vítimas de extenso genocídio".

3 Essa descentralização do sistema de ensino vige até hoje, embora passando por conotações específicas.

${ }^{4}$ Afora a inconstitucionalidade explícita com o art. $6^{\circ}$ da Constituição Imperial, essa lei provincial impede a presença, nos bancos escolares, de pessoas de "cor preta", vindas da África, ainda que não-escravizadas.

5 Cf. Cury, 2001.

${ }^{6}$ Cf. Cury, 2003.

7 Cf. SBPC, 1995.

${ }^{8}$ Cf. Rocha In: Fávero, 2001. 
9 Cf. Horta, 1994.

${ }^{10}$ Cf. Cunha, 2000; Cunha, 1981.

${ }^{11}$ Cf. Machado, 1989.

${ }^{12}$ Buffa, 1979; Saviani, 1973.

${ }^{13}$ Cf. Martins, 1997.

${ }^{14}$ Cf. Cury, 2005.

15 O reconhecimento à diferença teve, como caminho, trabalhos de denúncia, sobretudo, no âmbito de currículos discriminatórios entre os anos 1970 e 1980. Cf. Nosella, 1979; Rosenberg, 1980.

${ }^{16}$ Consulta em www.oei.es/quipu/Informe_preal2001.pdf, em 31/03/2008.

Recebido: 07/07/2008

Aprovado: 10/07/2008

Contato:

Avenida Dom José Gaspar, 500 - Prédio 40 - Sala 106

Coração Eucarístico

30535-610

Caixa Postal 2686

Belo Horizonte - MG

Brasil 